\title{
Gridded atmospheric emission inventory of 2,3,7,8-TCDD in China
}

\author{
Tao Huang a, Chongguo Tian ${ }^{\mathrm{b}}$, Kai Zhang ${ }^{\mathrm{a}}$, Hong Gao a, Yi-Fan $\mathrm{Li}^{\mathrm{c}}$, Jianmin Ma ${ }^{\mathrm{a}}$, * \\ a Key Laboratory for Environmental Pollution Prediction and Control, Gansu Province, College of Earth and Environmental Sciences, Lanzhou University, \\ Lanzhou 730000, China \\ ${ }^{\mathrm{b}}$ Key Laboratory of Coastal Zone Environmental Processes and Ecological Remediation, Yantai Institute of Coastal Zone Research, Chinese Academy of \\ Sciences, Yantai 264003, China \\ ${ }^{\mathrm{c}}$ International Joint Research Center for Persistent Toxic Substances (IJRC-PTS), State Key Laboratory of Urban Water Resource and Environment, Harbin \\ Institute of Technology, Harbin 150000, China
}

\section{H I G H L I G H T S}

- Dioxin emission in China accounted for about 30\% of global total emission in 2004.

- A gridded 2,3,7,8-TCDD emission inventory in 2009 over China was established.

- Metal production and waste incineration were identified as major sources of dioxin.

- Beijing-Tianjin-Hebei and Yangtze River Delta were major dioxin source regions.

\section{A R T I C L E I N F O}

\section{Article history:}

Received 18 August 2014

Received in revised form

23 February 2015

Accepted 26 February 2015

Available online 28 February 2015

\section{Keywords:}

Dioxin

2,3,7,8-TCDD

Gridded emission inventory

China

\begin{abstract}
A B S T R A C T
Establishment of the dioxins emission inventory has been considered as a crucial step toward risk assessment and elimination of dioxins contaminations. Based on a total dioxin emission inventory in China from different emission categories in 2004, this study created a gridded emission inventory of 2,3,7,8-TCDD, the most toxic congener in dioxins, in China in 2009 with a $1 / 4^{\circ}$ longitude by $1 / 4^{\circ}$ latitude resolution. It was estimated that annually total $371 \pm 53 \mathrm{~g}$ (average \pm standard deviation) of 2,3,7,8-TCDD was released into the atmosphere in 2009 over China, increasing approximately by $37 \%$ compared with its emission in 2004. Differing from most developed countries where municipal waste incinerations were regarded as a major atmospheric emission source, in China ferrous and non-ferrous metal production made the largest contribution to 2,3,7,8-TCDD air emission (138 $\pm 16 \mathrm{~g})$, followed by waste incineration $(109 \pm 12 \mathrm{~g})$, power and heating generation $(62 \pm 9 \mathrm{~g})$, and production of mineral products $(47 \pm 8 \mathrm{~g})$. The rest of sources contributed approximately $3 \%$ to the total 2,3,7,8-TCDD emission in 2009. Iron and steel industries are mainly located in Beijing-Tianjin-Hebei (BTH) and Yangtze River Delta (YRD) regions, whereas waste incinerators are mainly located in Pearl River Delta (PRD) region. Higher 2,3,7,8-TCDD emissions were found in these three regions. While the BTH, YRD, and PRD accounted for only about $4 \%$ of total land area of China, they contributed approximately $14 \%, 15 \%$, and $5 \%$ to the total $2,3,7,8-\mathrm{TCDD}$ emission in 2009 in China, respectively.
\end{abstract}

๑) 2015 Elsevier Ltd. All rights reserved.

\section{Introduction}

Polychlorinated dibenzo-p-dioxins/furans (PCDD/Fs), often termed dioxins, are notorious persistent organic pollutions (POPs). Their persistence in the environment and highly lipophilic property render them to bioaccumulate and biomagnify in food webs, posing

\footnotetext{
* Corresponding author. College of Earth and Environmental Sciences, Lanzhou University, 222, South Tianshui Road, Lanzhou 730000, China.

E-mail address: jianminma@lzu.edu.cn (J. Ma).
}

health risks to humans (Deng et al., 2012). Due to their semi-volatile property and long residence time in air, these compounds undergo long-range transport in the atmosphere, influencing the global environment (Daly and Wania, 2005; Lohmann and Jones, 1998).

Dioxins consist of over 200 congeners and are produced unintentionally by human activities, including waste incineration, metal production, electric power generation, chemical manufacturing, petroleum refining, fuel combustion in vehicles, and wood burning ( $G$.J. Zheng et al., 2008). A number of dioxins congeners have been unveiled to have toxic responses similar to those of $2,3,7,8$ - 
tetrachlorodibenzo-p-dioxin (2,3,7,8-TCDD). These toxic effects include dermal toxicity, immunotoxicity, reproductive effects and teratogenicity, endocrine disruption and carcinogenicity (WHO, 1998).

In order to modulate and reduce regional and global environmental exposure of POPs (including dioxins), the Stockholm Convention on POPs was established under the umbrella of the United Nations Environmental Programme (UNEP) and came into effect in 2004. Under this convention, the establishment of emission inventories for POPs is mandatory for the party countries because emission inventories are necessary for the assessment of environmental fate and health risks of POPs (UNEP, 1999, 2001; Vestreng and Klein, 2002). Emission data are also essential in POPs modeling and prediction of source-receptor relationships on regional (Van Jaarsveld et al., 1997; Cohen et al., 2002; Ma et al., 2004, 2005) and global scales (Wania et al., 1999; Wania and Daly, 2002).

In 1999, the UNEP published the report "Dioxin and Furan Inventories-National and Regional Emissions of PCDD/Fs" (UNEP, 1999). The report described PCDD/Fs emission inventories of 15 countries in 1995 and ranked the waste incineration as a major emitter in the majority of these 15 countries. Later, more countries established and reported their respective PCDD/Fs emission inventory, such as the United States (U.S.) in 1987, 1995, and 2000 (U.S. EPA, 2006), Canada in 1995 (Environment Canada, 1999), Japan in 2000 (Geng, 2011), and 27 member states of European Union (EU-27) for 1990-2010 (EEA, 2012). Based on the information of large point sources of $\mathrm{PCDD} / \mathrm{Fs}$ across Europe, gridded PCDD/Fs emission inventory $(50 \mathrm{~km} \times 50 \mathrm{~km})$ for these EU-27 member states were created at a national level and sectoral level for every five years from 1990 to 2010 (EEA, 2012). Cohen et al. (2002) collected PCDD/Fs emission data from facilities, industry groups, and/or regulatory agencies in each significant source category and established the gridded PCDD/Fs emission inventory $(100 \mathrm{~km} \times 100 \mathrm{~km})$ over the U.S. and Canada in 1996. They implemented this emission inventory in an atmospheric dispersion model to simulate the deposition of PCDD/F to the Great Lakes.

There has been increasing concern in China about PCDD/Fs contamination to its biotic and abiotic environments due to the rapid economic development and urbanization of China over the past 30 years. Dioxin contamination in China has been increased rapidly due to increasing concomitant industrialization, municipal solid waste, and unregulated electronic waste recycling activities. In 2008, China officially released its first domestic emission inventory of PCDD/Fs in 9 emission categories in 2004 at the national level. From this report, the annual dioxin emission in China from 10 source groups was estimated to be $10.2 \mathrm{~kg}$ TEQ in 2004 (M.H. Zheng et al., 2008), accounting for about $30 \%$ of the global total emissions (Lv et al., 2008). Iron and steel and other metal production industries were ranked as the biggest sources in China, accounting for $45.6 \%$ of the total emission, followed by power and heat generation, and waste incineration. Dioxins released from these three sources accounted for $81 \%$ of the total releases in China (M.H. Zheng et al., 2008). However, a gridded emission inventory for China is still not available yet. To fill this data gap, the present study made an effort to establish, for first ever, a gridded emission inventory of $2,3,7,8$ TCDD. This work also aimed to provide scientific support to scientists and policy makers to assess environmental fate and the impact of this toxic chemical on human health.

\section{Materials and methods}

The first domestic emission inventory of PCDD/Fs in China in 2004 (M.H. Zheng et al., 2008) reported the total PCDD/Fs emission in 9 categories at a provincial level. This inventory provided the raw data to the gridded emission inventory of 2,3,7,8-TCDD in 2009. Fig. 1 is a flow chart showing the major steps and procedures to construct the gridded 2,3,7,8-TCDD emission inventory in China. Firstly, based on the national PCDD/Fs emissions in different emission categories in 2004, we collected the provincial industrial activities in seven major dioxin-releasing categories from 20 industries. These seven categories are (1) iron and steel and other metal production, (2) power and heat generation, (3) waste incineration, (4) mineral products, (5) transportation, (6) field burning of crop straw, and (7) crematoria. These sources contributed to more than $98 \%$ of the total dioxin emission in China (M.H. Zheng et al. 2008). Detailed information for the distribution of provinces and the emission categories is presented in Supplement (text, Fig. A.1 and Table A.1), respectively. Secondly, the provincial PCDD/Fs emissions in the different categories in 2009 were constructed from the 2004 data by taking into account the differences in the activities of these industries between 2004 and 2009. Thirdly, using the fraction of 2,3,7,8-TCDD in total PCDD/Fs in different emission sectors, the provincial 2,3,7,8-TCDD emissions in 2009 in different categories were estimated. Finally, gridded population density, cropland coverage ratio, and the GDP from the secondary industry were used as surrogates data to establish gridded emission inventory for $2,3,7,8-\mathrm{TCDD}$ in China with $1 / 4^{\circ}$ longitude by $1 / 4^{\circ}$ latitude resolution.

\subsection{Calculation of provincial emissions in different categories}

Provincial total PCDD/Fs emission in different sectors in 2004 was estimated as follows:

$E_{i j, 2004}^{T}=E_{j, 2004}^{T} \times \frac{P_{i j, 2004}}{C_{j, 2004}}$

where $E_{i j}^{T}$ is total PCDD/F $\mathrm{F}_{\mathrm{s}}$ emission $(\mathrm{g})$ in sector $j$ and province $i$ in 2004. $E_{j}^{T}$ is total PCDD/F $\mathrm{F}_{\mathrm{S}}$ emission in sector $j$ in China. $P_{i j}$ is an activity rate $(\mathrm{kg} / \mathrm{yr}$ or $\mathrm{t} / \mathrm{yr})$, defined as the annual product from an industrial activity in one of dioxin-releasing categories in sector $j$ in province $i$. $C_{j}$ is the annual product in sector $j$ in whole country ( $\mathrm{kg} /$ yr or $\mathrm{t} / \mathrm{yr}$ ).

Likewise, the provincial total PCDD/Fs emission in different sectors in 2009 was estimated by

$E_{i j, 2009}^{T}=E_{i j, 2004}^{T} \times \frac{P_{i j, 2009}}{P_{i j, 2004}}$

Knowing the fraction of $2,3,7,8-\mathrm{TCDD}$ in total PCDD/Fs in different emission sectors, the provincial 2,3,7,8-TCDD emission in these sectors can be defined by

$E_{i j, 2009}=E_{i j, 2009}^{T} \times F_{j}$

where $F_{j}$ is the fraction of $2,3,7,8-\mathrm{TCDD}$ in total PCDD/Fs in the sector $j$. Annual or daily industrial activities determining different dioxin sources were mostly obtained from statistical data released by National Bureau of Statistics of China (NBSC), and other reliable documents from governmental agencies or industries. The fraction of 2,3,7,8-TCDD in total PCDD/Fs was collected mainly from monitored data in different emission sectors in China, and emission data from other countries. The detail information for activity rate and the fraction of 2,3,7,8-TCDD in total PCDD/Fs in different emission sectors are presented in Table A.1.

\subsection{Emission gridding}

Dioxin might be extensively emitted in some areas but less or 


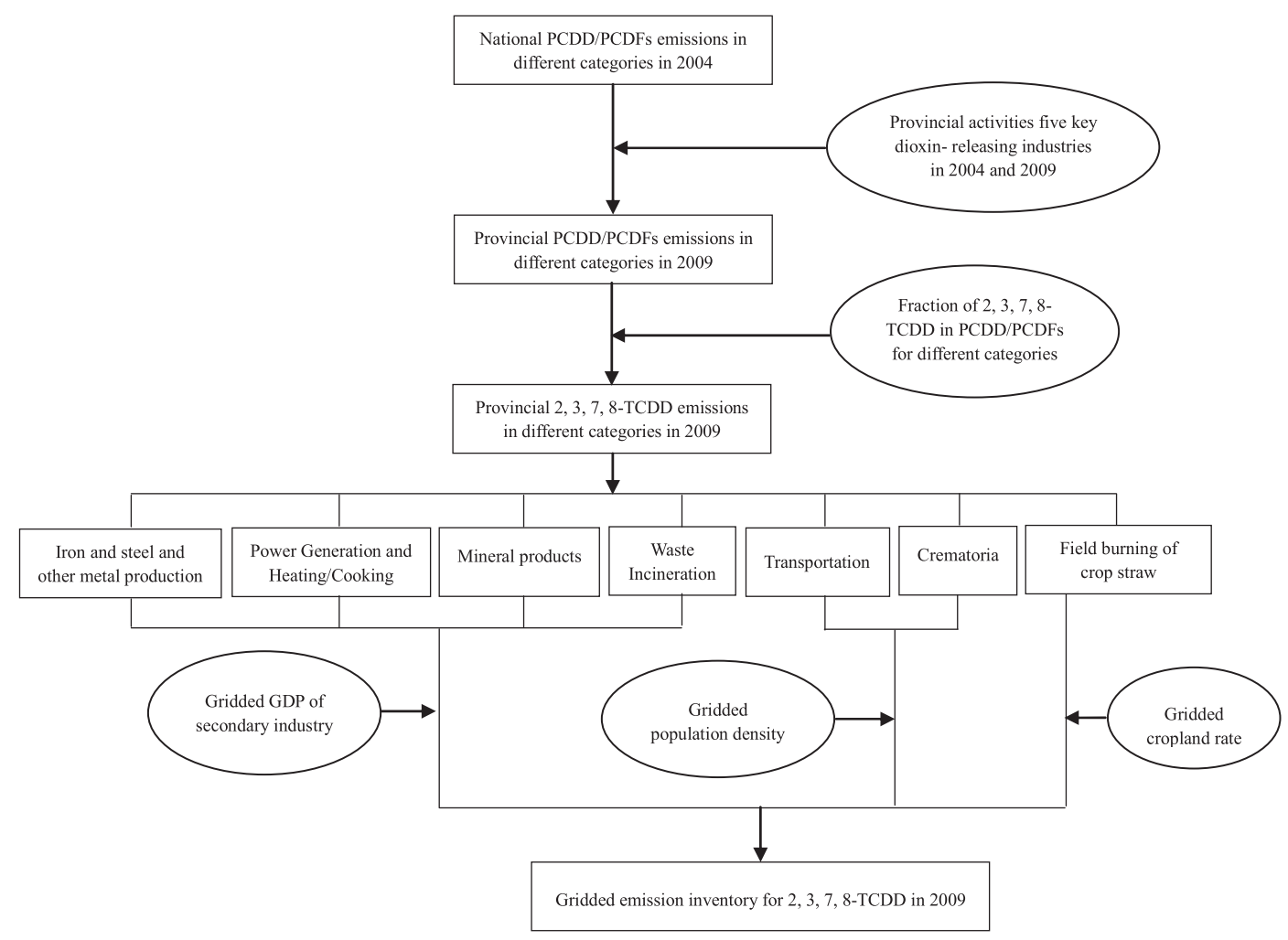

Fig. 1. Flow chart showing steps and procedures for updating and establishing gridded 2,3,7,8-TCDD emission inventory in 2009 from 2004 provincial emission data.

not be emitted in other areas. The purpose of the dioxin emission gridding is to allocate the dioxin emission to the areas where dioxin actually is emitted. In order to allocate provincial $2,3,7,8-\mathrm{TCDD}$ emission data to a spatial grid, it is necessary to selecte and determine appropriate surrogate data. Using population densities in each country as a surrogate parameter, Brievik et al. (2002) have developed gridded global PCBs air emission inventories by allocating national total emissions to the GEIA (Global Emission Inventory Activity) grid system $\left(1^{\circ} \times 1^{\circ}\right)$ in each country. The global gridded inventories of $\alpha-\mathrm{HCH}$ and $\gamma-\mathrm{HCH}$ usage with a $1 / 4^{\circ}$ longitude by $1 / 6^{\circ}$ latitude resolution were also constructed by using a global arable land density dataset from Earth Resources Observation and Science (EROS) as surrogate data (Li, 1999). By taking into sufficient consideration of major source characteristics of dioxins, a regression analysis was performed to discern significant statistical relationships between provincial total PCDD/Fs release in different category and provincial population density, the GDP from the secondary industry, and arable land density, respectively, in order to select the most appropriate surrogate data to allocate provincial emission data to a spatial grid. The strong and significant correlations were found between provincial total PCDD/Fs release and these surrogate data (Fig. A.2). With these relationships and following the similar approaches adopted in previous studies to establish gridded POPs usage/emission inventories (Brievik et al., 2002; Li, 1999; Zhao, 2005), the three surrogate datasets were employed in the present study to grid the emission of 2,3,7,8-TCDD in different source categories (Fig. A.3). These are the gridded population density, night light intensity, and cropland density.

The global gridded population density $\left(2.5^{\prime}\right.$ latitude by $2.5^{\prime}$ longitude) in 2010 and gridded cropland datasets ( $5^{\prime}$ latitude by $5^{\prime}$ longitude) in 2000 are available from the CIESIN (Center for International Earth Science Information Network) of Columbia University (available at http://sedac.ciesin.columbia.edu/data/sets).
Considering insignificant change in gridded population density between 2009 and 2010, and the croplands between 2000 and 2009 , these data were adopted in the present study to derive the gridded emission inventory in 2009 (Yu et al., 2012).

Due to the scarcity of regional and local GDP data, night lights intensities measured by satellites instruments have been used as a proxy to supplement the official statistics on the growth rate of GDP. Night time lights data have been used to study economic activities for the last two decades. Doll et al. (2000) have used global night time datasets to produce the global map of GDP-PPP (Purchasing Power Parity) at a resolution of $1^{\circ}$ latitude by $1^{\circ}$ longitude. Han et al. (2012) created gridded GDP map at $1 \mathrm{~km}$ resolution over China using logarithmic regression models between different night light indexes and the GDP from primary industry, secondary industry, and tertiary industry. Following Han et al. (2012) and using the Defense Meteorological Satellite Program/Operational Linescan System (DMSP/OLS) night-time light data in 2009 (Fig. A.3) (available at the NGDC website (National Geophysical Data Center), http://ngdc.noaa.gov/eog/dmsp/downloadV4composites.html), the GDP from the secondary industry in China at $1 \mathrm{~km}$ resolution was calculated by:

$\ln G D P_{2}=0.733 \ln I+14.424$

where $\mathrm{GDP}_{2}$ is the GDP from the secondary industry (10,000 yuan/ $\mathrm{km}^{2}$ ), and $I$ is the night light index (dimensionless). Efforts were also made to associate 2,3,7,8-TCDD emissions from major secondary industrial activities (ferrous and non-ferrous metal, power generation and heating, waste incineration, and mineral products) with population densities. Results show that there are no statistically significant relationships between the emissions from these secondary industrial activities and population density.

The population density, the GDP from the secondary industry, and cropland were compiled to the model grids $\left(1 / 4^{\circ} \times 1 / 4^{\circ}\right.$ 
latitude/longitude). Details are presented in Fig. A.3.

\subsection{Air concentration calculated based on emission inventory}

To enhance the level of confidence in the gridded 2,3,7,8-TCDD emission inventory established in the present study, a simplified Gaussian dispersion model for a point source was applied to convert the gridded emissions to the annually averaged gridded air concentrations. Results were then compared with available monitored air concentrations of 2,3,7,8-TCDD across China in 2009. This simplified Gaussian model for a point source reads (Jiang and Wu, 1990):

$C_{i}=E /\left(u_{i} \Delta l \Delta h\right)$

where $C_{i}$ is air concentration at each grid cell on day $i\left(\mathrm{pg} / \mathrm{m}^{3}\right), E$ is the emission rate at the grid cell $(\mathrm{g} / \mathrm{yr}), \Delta l$ is the dimension of the grid cell $(27.83 \mathrm{~km}), \Delta h$ is the height $(\mathrm{m})$ of an air sampler of dioxins above the ground surface, which is assumed to be $10 \mathrm{~m}$ in this study, and $u_{i}$ is the mean wind speed $(\mathrm{m} / \mathrm{s})$.

$u_{i}=\sqrt{u_{x i}^{2}+v_{y i}^{2}}$

where $u_{x i}$ and $v_{x i}$ is the mean horizontal wind component in $\mathrm{x}$ and $\mathrm{y}$ direction, respectively, collected from the National Centers for Environmental Prediction (NCEP) reanalysis at the surface level (http://www.esrl.noaa.gov/psd/data/gridded/data.ncep.reanalysis. html). The NCEP wind data were then interpolated into the emission inventory grids $\left(1 / 4^{\circ} \times 1 / 4^{\circ}\right.$ latitude/longitude). No unified sampling height has been ever reported in those field programs conducted in China. As an alternative, we have also estimated the air concentrations using Eq. (5) by assuming $\Delta h=1.5 \mathrm{~m}$. The correlation between the monitored and computed concentrations $(\mathrm{r}=0.78)$ is also significant but lower slightly than that using $\Delta h=10 \mathrm{~m}(\mathrm{r}=0.83$, Section 5 in Supplement). Eq. (5) using $\Delta h=1.5 \mathrm{~m}$ also overestimated air concentrations as compared with that derived from $\Delta h=10 \mathrm{~m}$.

\section{Results and discussions}

\subsection{Total 2,3,7,8-TCDD emission based on categories}

2,3,7,8-TCDD released from different sources into the atmosphere were summarized in Table 1 . Results show that China emitted $304.6 \pm 42.3 \mathrm{~g}$ in 2004 and $370.6 \pm 52.5 \mathrm{~g}$ 2,3,7,8-TCDD in 2009 to the atmosphere, respectively, with an annually averaged increasing rate of $3.5 \%$ from 2004 to 2009 . Analogous to the total dioxin, ferrous and non-ferrous metal production also made the largest contribution to 2,3,7,8-TCDD emission (37\%), followed by waste incineration (29\%), power and heating generation (18\%), and production of mineral products (13\%). The other sources contributed approximately $3 \%$ to the total $2,3,7,8-\mathrm{TCDD}$ emission in 2009.

China has been undergoing rapid industrialization since the early 1980s, especially in metal production industries. The output of crude steel and raw iron increased from 0.26 billion tones in 2000 to 1.33 billion tones in 2010 (NBSC, 2001, 2011), at an annual increase rate of $37 \%$ for the 2000 s. The rapid expansion of metal production industries resulted in the rapid increasing of $2,3,7,8$ TCDD emission by 31\% in 2009 from 2004.

Electricity generation from coal fired power and heat production from industrial boiler in 2009 were reported to increase approximately 1.5 and 1.8 fold as compared with that in 2004 (NBSC, 2005a, 2010a). However, due to the decline of rural residential energy consumption for stalks and firewood (NBSC, 2005b, 2010b), 2,3,7,8-TCDD emission from power and heating generation in 2009 reduced by $20 \%$ from the 2004 level.

With the rapid development of economy and great improvement of living standards in China, a large amount of municipal solid waste (MSW) have been produced, reaching about 360 million tonnes per year with an annual increasing rate of $8 \%$ from 2005 to 2010 (Yu, 2012). The lack of landfill sites forced local governments to choose incineration as an alternate method in waste disposal. As a result, since 2000 , the construction of municipal solid waste incinerators (MSWIs) has been booming and by 2005, 67 MSWI facilities were running with a total daily MSW treatment capacity of 33,000 tones (Xu and Liu, 2007). It has been reported that China will build 300 incinerators, capable of handling $30 \times 10^{4}$ tonnes of garbage per day, or $\sim 30 \%$ of the total solid waste over China by 2015 (MEPC, 2012). On the other hand, as the largest developing country, China has been also generating huge amounts of hazardous waste every year. Incineration is an ultimate disposal approach for hazardous wastes which cannot be safely deposited, reduced or recycled in a secured landfill site (Visvanathan, 1996). Compared with traditional hazardous waste disposal technologies, incineration incorporates weight and volume reduction, detoxification and energy recovery. At present, incineration has been regarded as a priority disposal method in hazardous waste treatment in "the Nation Plan for Construction of Facilities for Disposal of Hazardous Wastes and Medical Wastes", which was established by the National Development and Reform Commission and State Environmental Protection Administration of China (Chen et al., 2008). Along with national wide construction of HWIs (Ma et al., 2011; Wu et al., 2012), waste incineration has become the second biggest 2,3,7,8-TCDD emission source in China in 2009. With increasing hazardous waste and the transformation of hazardous waste treatment disposal pattern from landfill to incineration, the dioxin emissions from this source will increase continually in the future in China.

Owing to the nationwide high demand to constructions in China, mineral products industries has been also undergoing rapid development. For example, the output of cement in 2009 increased

Table 1

Atmospheric 2,3,7,8-TCDD emission based on different emission categories in China.

\begin{tabular}{|c|c|c|c|c|c|}
\hline & \multicolumn{2}{|l|}{2004} & \multicolumn{2}{|l|}{2009} & \multirow[t]{2}{*}{ Change rate (\%) } \\
\hline & Average \pm Std Dev (g) & Average percentage (\%) & Average \pm Std Dev (g) & Average percentage (\%) & \\
\hline Ferrous and non-ferrous metal production & $105.3 \pm 12.3$ & 34.6 & $138.3 \pm 16.2$ & 37.3 & 31.3 \\
\hline Power and heating generation & $77.4 \pm 7.2$ & 25.4 & $61.6 \pm 8.7$ & 16.7 & -20.4 \\
\hline Waste incineration & $64.2 \pm 6.0$ & 21.1 & $108.9 \pm 12.1$ & 29.4 & 69.6 \\
\hline Production of mineral products & $44.3 \pm 5.8$ & 14.5 & $46.8 \pm 7.8$ & 12.6 & 5.6 \\
\hline Transportation & $9.00 \pm 2.0$ & 2.9 & $11.5 \pm 2.0$ & 3.1 & 27.8 \\
\hline Field burning of crop straw & $3.2 \pm 0.6$ & 1.1 & $2.3 \pm 0.6$ & 0.6 & -28.1 \\
\hline Crematoria & $1.2 \pm 0.3$ & 0.4 & $1.2 \pm 0.2$ & 0.3 & 3.0 \\
\hline Total & $304.6 \pm 42.3$ & 100 & $370.6 \pm 52.5$ & 100 & 21.7 \\
\hline
\end{tabular}


approximately 1.5 fold as compared with that in 2004 (NBSC, 2005a, 2010a). As a result, 2,3,7,8-TCDD emitted from the mineral products increased from $44.3 \pm 5.8 \mathrm{~g}$ in 2004 to $46.8 \pm 7.8 \mathrm{~g}$ in 2009

Compared with 2004, 2,3,7,8-TCDD emission from transportation increased $28 \%$ due to increasing auto possessive quantity in 2009. On the other hand, 2,3,7,8-TCDD emission from field burning of crop straw in 2009 decreased by almost 30\% from 2004. Whereas, the emission from crematoria did not alter considerably during the period of 2004-2009 (Table 1).

\subsection{Gridded 2,3,7,8-TCDD emission}

Fig. A.4a depicts provincial 2,3,7,8-TCDD emission in 2009 in China. Results show that Hebei province emitted the highest level of 2,3,7,8-TCDD into the atmosphere with the total emission at $36.5 \mathrm{~g}$, followed by Jiangsu province (34.1 g), Shandong Province (30.4 g), Guangdong Province (27.2 g), and Zhejiang Province (26.8 g). More information of 2,3,7,8-TCDD emission at provincial level from different sources is presented in Supplement (text, Fig. A.4).

Provincial emission of $2,3,7,8-T C D D$ only reports the total emission in that province but cannot identify non-uniform distribution of the emission strength across the province. In reality, 2,3,7,8-TCDD could be emitted to air in a large amount in some regions and little or not be emitted to other regions, such as western China. Such provincial emission inventory could create uncertainties in the assessment of point emission sources and could not be used in an air pollution model to quantify the sourcereceptor relationships and atmospheric transport of this toxic chemical over China. Such drawbacks could be overcome by a gridded emission inventory at a relatively high spatial resolution.

Fig. 2 shows the gridded 2,3,7,8-TCDD emission in China in 2009 with a $1 / 4^{\circ}$ longitude by $1 / 4^{\circ}$ latitude resolution from different source sectors. As seen from Fig. 2a, total 2,3,7,8-TCDD emissions were higher in those regions with higher population density and stronger industrial activities. Particularly, higher 2,3,7,8-TCDD emissions were estimated in Beijing-Tianjin-Hebei (BTH), Yangtze River Delta (YRD), and Pearl River Delta (PRD) region. While these three regions accounted for only about $4 \%$ of total land area of mainland China, they contributed $14 \%, 15 \%$, and $5 \%$ to the total 2,3,7,8-TCDD emission in 2009 in China, respectively.

Higher 2,3,7,8-TCDD emissions from ferrous and non-ferrous metal production were estimated in central Hebei, Tianjin, and YRD, and central Liaoning (Fig. 2b). China's steel industries are mainly located in Hebei, Jiangsu, and Liaoning provinces. The crude steel production from these three provinces accounted for $42 \%$ of the national total production in China in 2009 (NBSC, 2005a, 2010a). There were relatively higher 2,3,7,8-TCDD emission from power and heating generation, and mineral products in BTH, YRD, and PRD regions. In addition, northern Henan and central Sichuan basin were also large source regions of 2,3,7,8-TCDD from their power and heating generation and mineral products (Fig. 2c, e). Landfill is the dominant municipal solid waste (MSW) disposal method in China, accounting for more than $80 \%$ of the MSW disposal (Li et al., 2004). However, as aforementioned, the number of large-scale MSW incinerator plants has gradually increased in mega cities in eastern China. In 1988, the first MSWI, a Martin grate imported from Mitsubishi Co., Japan, was built in Shenzhen, China. Since then, more MSW incinerators plants have been constructed in Beijing, Shanghai, Guangzhou and other big cities (Yan et al., 2006). Accordingly, 2,3,7,8-TCDD emissions from waste incineration were mainly found in the BTH, YRD, and PRD regions (Fig. 2d). Higher 2,3,7,8-TCDD emission from transportation and crematoria were mostly estimated in well developed eastern and coastal cities, such as Beijing, Shanghai, Tianjin, and PRD (Fig. 2f, h). Burning crop residues in field can obviously improve the content of available soil nutrients, kill weeds, and benefit crop growth (Wang et al., 2003), which greatly increases the probability of biomass burning. Biomass burning assessment indicates that the amount of biomass burned in China is about 140 million tons each year (Cao et al., 2005). The higher 2,3,7,8-TCDD emissions from field burning of crop straw were found in Shandong, Jiangsu, western Henan, northern Hebei, central Heilongjiang and Jilin, and eastern Hubei due to their large cropland areas (Fig. $2 \mathrm{~g}$ ).

\subsection{Comparison to monitored air concentration}

To validate the 2,3,7,8-TCDD emission inventory created in the present study, annually averaged 2,3,7,8-TCDD air concentrations were estimated using the simplified Gaussian dispersion model for a point source (Eq. (5)). The converted air concentrations were illustrated in Fig. A.5 and compared with monitored air concentration data collected in 2009 from literature across China. Values of these monitored air concentrations data are listed in Table A.2. Result from the comparison between the converted and measured concentrations were shown in Fig. A.6 and Table A.2. It is worthwhile to note that most measured dioxins air concentrations were collected at a single or multiple sites within urban centers where dioxins concentrations were expected to be higher than that in surrounding suburban and rural areas, or vice versa. In addition, the estimated 2,3,7,8-TCDD concentration at a model grid with grid spacing of $27.83 \times 27.83 \mathrm{~km}^{2}\left(1 / 4^{\circ} \times 1 / 4^{\circ}\right.$ latitude/longitude $)$ stands for the mean concentration over the grid cell which often includes both urban and rural areas. Large spatial variability in the measured 2,3,7,8-TCDD concentrations might contribute to the differences between the modeled and measured 2,3,7,8-TCDD concentrations. For example, the measured 2,3,7,8-TCDD air concentrations ranged from 0.009 to $0.026 \mathrm{pg} / \mathrm{m}^{3}$ at different sites over an area of $12 \mathrm{~km}^{2}$ in Tianjin, a mega city near Beijing (Ding et al., 2012). Because measured 2,3,7,8-TCDD air concentrations were reported at only limited number of sites in big cities and collected during a short period of time, the deviations of the monitored concentrations from the annual mean concentrations derived from the annual emission (Eq. (5)) were expected. Nevertheless, as seen from Fig. A.6, the converted air concentrations from the emission inventory by the simplified Gaussian dispersion model match very well with the measured data, as demonstrated by the correlation coefficient of $r=0.83(p<0.01)$ and small values of error quotients (EQs, Table A.2), ranging from 0.25 to 2.1. It should be noted that, given difficulties in monitoring and analyzing dioxin atmospheric concentrations, measured ambient air concentrations were scarce across China. The significance in correlations between estimated and sampled 2,3,7,8-TCDD concentrations is expected to change with increasing or decreasing number of sampling sites.

\subsection{Uncertainty analysis}

Given potential errors in emission factors and industrial data from different emission sectors, uncertainty analysis for emission data is necessary to validate an emission inventory. In the present study, 2,3,7,8-TCDD emissions were derived from the total dioxin emission from different source sectors in 2004, activity levels of different emission industries in different provinces which released dioxins, and the fraction of 2,3,7,8-TCDD in total dioxin in different industries. Most emission factors used to calculate total dioxin emission from different sources in China in 2004 were obtained from the standardized toolkit of dioxin release recommended by the UNEP (2005). Due to the lack of routine monitoring data, the activity levels of different dioxin releasing industries may have statistical errors. The fraction of 2,3,7,8-TCDD in total dioxin used in 


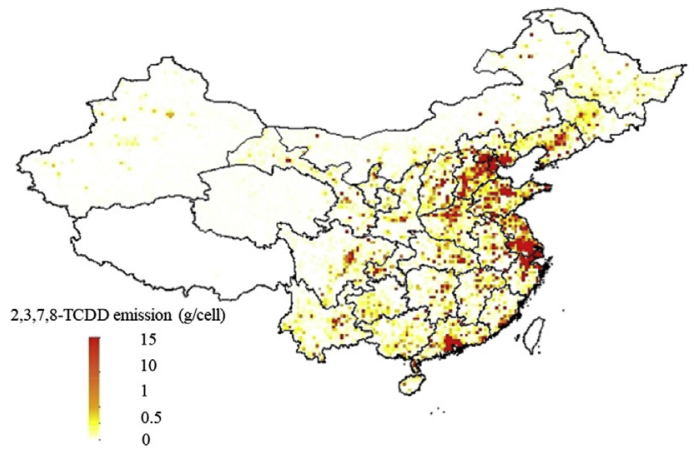

(a)

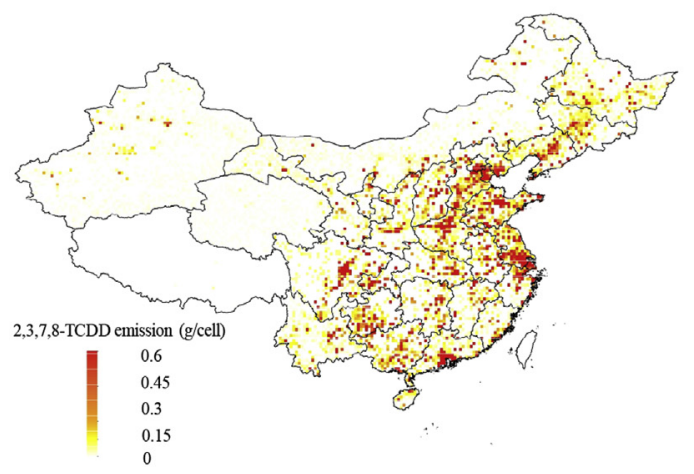

(c)

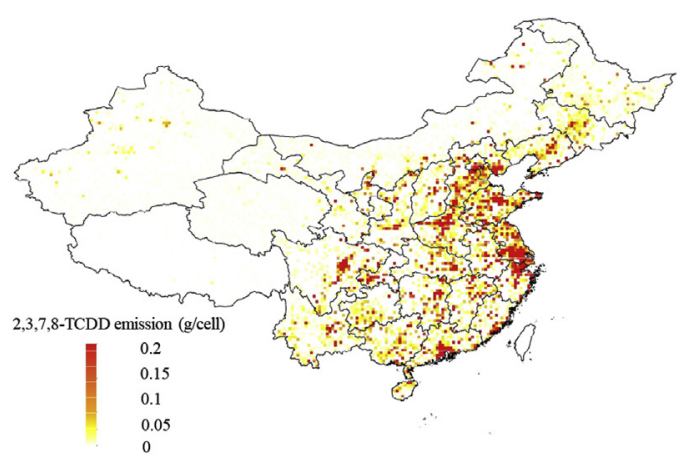

(e)

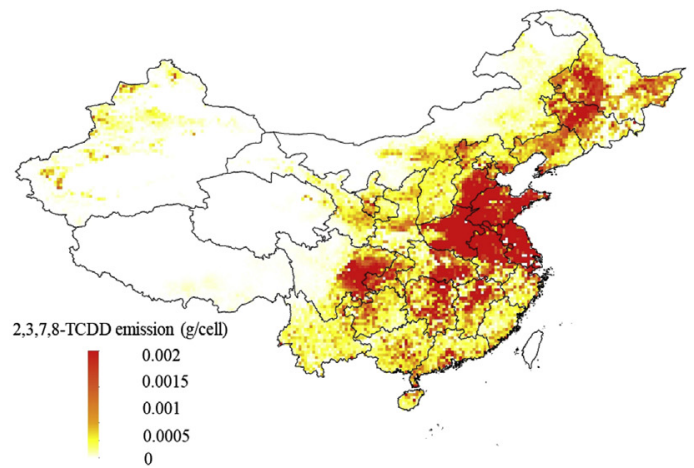

(g)

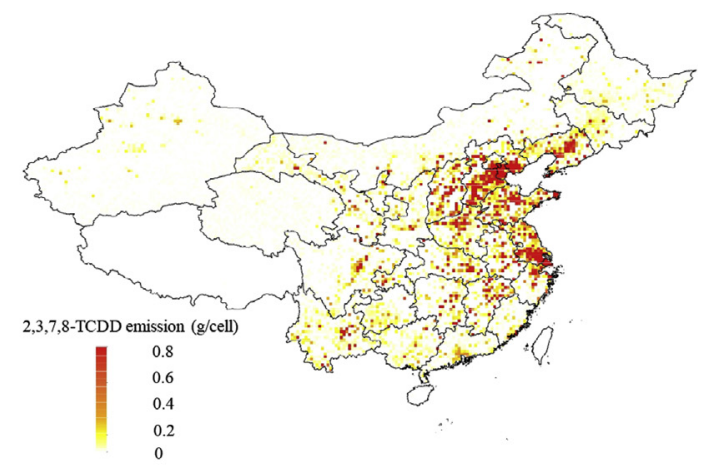

(b)

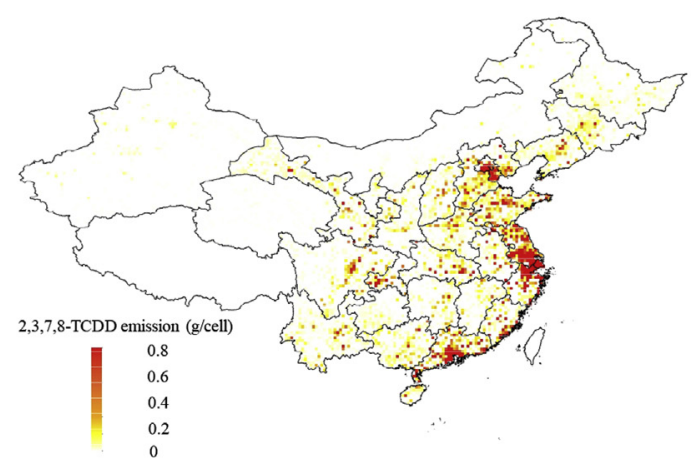

(d)

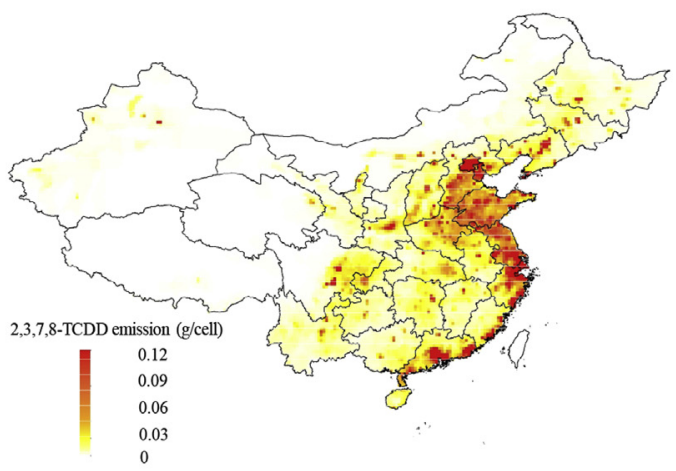

(f)

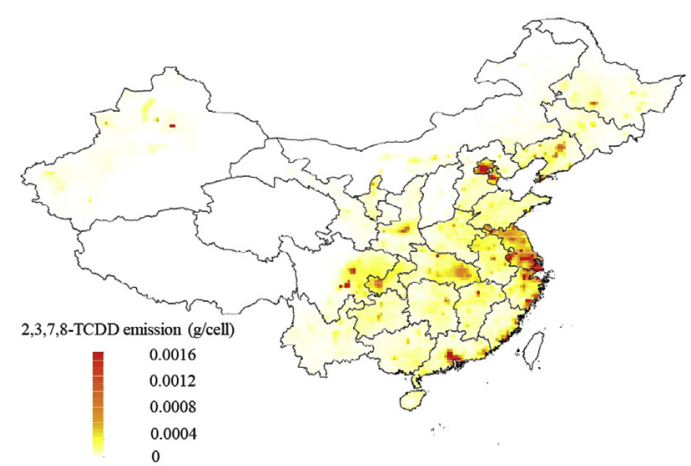

(h)

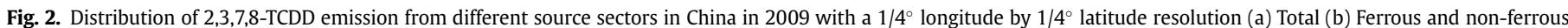

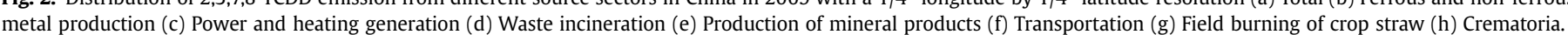




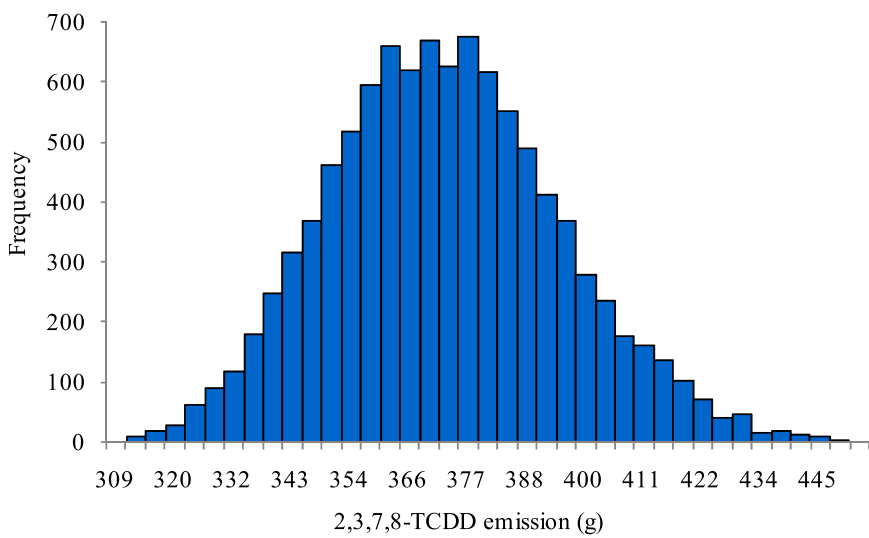

Fig. 3. Frequency distribution of total 2,3,7,8-TCDD emission.

this study were collected partly from monitored data of individual industrial sector which released dioxin in China, and partly from existing results from emission data of other countries (Table A.1). All these factors may create uncertainties in the construction of gridded dioxin emission inventory. Surrogate data were used merely to allocate provincial level emissions to grid cells which would neither change the amount of total emissions at provincial and national level, nor the emissions from different emission sectors and categories. Hence, the uncertainties from the surrogate data in the establishment of the emission inventory were not tested here. A Monte Carlo technique (Cao et al., 2004; Tian et al., 2013) was used to evaluate the uncertainties of 2,3,7,8-TCDD emission inventory. In the uncertainty analysis, the coefficient of variation $(\mathrm{CV}, \%)$ for the fraction of $2,3,7,8-\mathrm{TCDD}$ ranged from $11 \%$ to $36 \%$ (Table A.1), and the CV for industrial activity levels was set to $30 \%$. Each input parameter was treated as a random variable with the normal distribution. The calculation of inventory was run repeatedly 10,000 times at the $95 \%$ confidence level. The uncertainty for total 2,3,7,8-TCDD emission was shown in Fig. 3 and Table A.3, respectively. As seen, total 2,3,7,8-TCDD emission varied widely and reached a normal distribution, ranging from $309 \mathrm{~g}$ to $452.4 \mathrm{~g}$. Compared with 2,3,7,8-TCDD emission estimated in this study ( $370.6 \mathrm{~g}$ ), the variation ranged from $-16 \%$ to $22 \%$. Analogous to the total 2,3,7,8-TCDD emission, modeled 2,3,7,8-TCDD emission from different sources also varied widely and reached a normal distribution (Fig. A.7 and Table A.3). Compare with the calculated annual emission, the field burning of crop straw displayed the largest coefficient of variation (25\%), followed by transportation (18\%), production of mineral products (17\%), crematoria (16\%), power and heating generation (14\%), ferrous and non-ferrous metal production (12\%), and waste incineration (11\%).

\section{Conclusions}

Based on the total dioxin emission inventory in different provinces and different categories in 2004, this study established the gridded 2,3,7,8-TCDD emission inventory in 2009 with a $1 / 4^{\circ}$ longitude by $1 / 4^{\circ}$ latitude resolution over China. The inventory used provincial activity levels of different emission industries, the secondary industry GDP, population density, and cropland coverage rate as surrogates to allocate the emissions to specified model grids. It was estimated that a total $371 \pm 52 \mathrm{~g}$ (average \pm standard deviation values) of 2,3,7,8-TCDD was released annually in 2009, increasing by approximately 37\% from 2004. Ferrous and nonferrous metal production made the largest contribution to 2,3,7,8TCDD emission at the annual release of $128 \pm 19 \mathrm{~g}$, followed by waste incineration $(109 \pm 12 \mathrm{~g})$, power and heating generation
$(62 \pm 9 \mathrm{~g})$, and production of mineral products $(47 \pm 8 \mathrm{~g})$. The rest sources contributed approximately $3 \%$ to the total $2,3,7,8-T C D D$ emission in 2009. According to the results from this study, Hebei province released most 2,3,7,8-TCDD into the air in China at the annual total emission of $37 \pm 7 \mathrm{~g}$ in 2009 , followed by Jiangsu ( $34 \pm 5 \mathrm{~g})$, Shandong ( $30 \pm 4 \mathrm{~g}$ ), Guangdong ( $27 \pm 3 \mathrm{~g}$ ), and Zhejiang province $(27 \pm 3 \mathrm{~g}) \cdot 2,3,7,8$-TCDD emission from these regions accounted for $42 \%$ of the total emission in China in 2009. While Beijing-Tianjin-Hebei (BTH), Yangze River Delta (YRD), and Pearl River Delta (PRD) regions accounted for only about $4 \%$ of total land area of China, these three regions contributed approximately $14 \%$, $15 \%$, and $5 \%$ to the total $2,3,7,8-\mathrm{TCDD}$ emission in 2009 in China, respectively.

The gridded 2,3,7,8-TCDD emission inventory established in this study provides a useful tool for environmental fate modeling and assessment of human exposure risk of this toxic chemical. It also provides a useful dataset and scientific support to policy makers and stakeholders to evaluate, assess, and make corresponding emission reduction measures to dioxin contaminations in China.

\section{Acknowledgment}

This research was supported by the National Science Foundation of China (Grants 41371478 and 41371453), and Fundamental Research Funds for the Central Universities (lzujbky-2014-130).

\section{Appendix A. Supplementary data}

Supplementary data related to this article can be found at http:// dx.doi.org/10.1016/j.atmosenv.2015.02.070.

\section{References}

Brievik, K., Sweetman, A., Pacyna, J.M., 2002. Towards a global historical emission inventory for selected PCB congeners a mass balance approach. 1. Global production and consumption. Sci. Total Environ. 290, 181-198.

Cao, G., Zhang, X., Wang, D., Zheng, F., 2005. Inventory of atmospheric pollutants discharged from biomass burning in China continent. Chin. Environ. Sci. 25, 389-393.

Cao, H., Tao, S., Xu, F., Coveney, R.M., Cao, J., Li, B., 2004. Multimedia fate model for hexachlorocyclohexane in Tianjin, China. Environ. Sci. Technol. 38, 2126-2132.

Chen, T., Yan, J.H., Lu, S.Y., Li, X.D., Gu, Y.L., Dai, H.F., Ni, M.J., Cen, K.F., 2008. Characteristic of polychlorinated dibenzo-p-dioxins and dibenzofurans in fly ash from incinerators in China. J. Hazard. Mater. 150, 510-514.

Cohen, M.D., Draxler, R.R., Artz, R., Bartlett, P., Cooney, P., Couchot, K., 2002. Modeling the atmospheric transport and deposition of PCDD/F to the Great Lakes. Environ. Sci. Technol. 36, 4831-4845.

Daly, G.L., Wania, F., 2005. Organic contaminants in mountains. Environ. Sci. Technol. 39, 385-398.

Deng, B., Zhang, J., Zhang, L., Jiang, Y., Zhou, J., Fang, D., Zhang, H., Huang, H., 2012. Levels and profiles of PCDD/Fs, PCBs in mothers' milk in Shenzhen of China: estimation of breast-fed infants' intakes. Environ. Int. 42, 47-52.

Ding, L., Li, Y., Wang, P., Li, X., Zhao, Z., Zhang, Q., Tuan, T., Jiang, G., 2012. Seasonal trend of ambient PCDD/Fs in Tianjin City, northern China using active sampling strategy. J. Environ. Sci. China 24, 1966-1971.

Doll, C.N.H., Muller, J.P., Elvidge, C.D., 2000. Night-time imagery as a tool for global mapping of socioeconomic parameters and greenhouse gas emissions. AMBIO A J. Hum. Environ. 29, 157-162.

EEA (European Environment Agency), 2012. European Union Emission Inventory Report 1990-2010 under the UNECE Convention on Long-range Transboundary Air Pollution (LRTAP). European Environment Agency, Copenhagen.

Environment Canada, 1999. Dioxins and furans and hexachlorobenzene inventory of releases. Prepared for the Federal Provincial Advisory Committee for the Canadian Environmental Protection Act, 1999.

Geng, J., 2011. Analysis of Control Policy of Dioxins. Metallurgical Industry Press, Beijing.

Han, X., Zhou, Y., Wang, S., Liu, R., Yao, Y., 2012. GDP spatialization in China based on nighttime imagery. J. Geo Inf. Sci. 14, 128-136.

Jiang, W., Wu, X., 1990. A linked three-dimensional PBL and dispersion model in coastal regions. Bound. Layer Meteorol. 53, 43-62.

Li, M., Xiang, J., Hu, S., Sun, L.S., Su, S., Li, P.S., Sun, X.X., 2004. Characterization of solid residues from municipal solid waste incinerator. Fuel 83, 1397-1405.

Li, Y.F., 1999. Global gridded technical hexachlorocyclohexane usage inventories using a global cropland coverage rate as a surrogate. J. Geophys. Res. Atmos. 104, 23785-23797. 
Lohmann, R., Jones, K.C., 1998. Dioxins and furans in air and deposition: a review of levels, behaviour and processes. Sci. Total Environ. 219, 53-81.

Lv, Y.H., Huang, J., Yu, G., Yang, X., 2008. Comparison of the dioxin release inventories of China and other countries. Environ. Pollut. Control 30, 71-74.

Ma, J., Daggupaty, S., Harner, T., Li, Y., 2004. Impacts of lindane usage in the Canadian Prairies on the Great Lakes ecosystem. 1. Coupled atmospheric transport model and modeled concentrations in air and soil. Environ. Sci. Technol. 37, 3774-3781.

Ma, J., Venkatesh, S., Li, Y., Cao, Z., Daggupaty, S., 2005. Tracking toxaphene in the North American Great Lakes Basin. 2. A strong episodic long-range transport event. Environ. Sci. Technol. 39, 8132-8141.

Ma, P., Ma, Z.Y., Yan, J.H., Chi, Y., Ni, M.J., Cen, K.F., 2011. Industrial hazardous waste treatment featuring a rotary kiln and grate furnace incinerator: a case study in China. Waste Manag. Res. 29, 1108-1112.

MEPC (Ministry of Environmental Protection of China), 2012. National "Twelfth Five Year Plan" for Prevention and Control Hazardous Waste Pollution. Ministry of Environmental Protection of China, Beijing.

NBSC (National Bureau of Statistics of China), 2001. China Statistical Yearbook 2001. China Statistics Press, Beijing.

NBSC (National Bureau of Statistics of China), 2005. China Statistical Yearbook 2005a. China Statistics Press, Beijing.

NBSC (National Bureau of Statistics of China), 2010. China Statistical Yearbook 2010a. China Statistics Press, Beijing.

NBSC (National Bureau of Statistics of China), 2011. China Statistical Yearbook 2011. China Statistics Press, Beijing.

NBSC (National Bureau of Statistics of China), 2005. China Energy Statistical Yearbook 2005b. China Statistics Press, Beijing.

NBSC (National Bureau of Statistics of China), 2010. China Energy Statistical Yearbook 2010b. China Statistics Press, Beijing.

Tian, H., Guo, O, Fang, L. Mao, X., Huang, T., Wu, J.N., Ma, J.M., Gao, H., 2013. Stimulation of multimedia transfer and fate of endosulfan in semi-arid area: a case study in Lanzhou, a valley-basin city in Western China. Acta Sci. Circumst. 33, $1110-1117$.

UNEP (United Nations Environmental Programme), 1999. Dioxin and Furan Inventories: National and Regional Emissions of PCDD/F. Prepared by UNEP Chemicals. United Nations Environment Programme, Geneva, Switzerland.

UNEP (United Nations Environmental Programme), 2001. The Stockholm Convention on Persistent Organic Pollutants. United Nations Environmental Programme, Geneva, Switzerland.

UNEP (United Nations Environmental Programme), 2005. Standardized Toolkit for Identification and Quantification of Dioxin and Furan Releases. United Nations Environmental Programme Chemicals, Geneva, Switzerland.

U.S. EPA (the US Environmental Protection Agency), 2006. An Inventory of Sources and Environmental Releases of Dioxin-like Compounds in the United States for the Years 1987, 1995, and 2000. U.S. Environmental Protection Agency, Washington, D.C.

Van Jaarsveld, J.A., Van Pul, W.A.J., De Leeuw, F.A., 1997. Modeling transport and deposition of persistent organic pollutants in the European region. Atmos. Environ. 31, 1011-1024.

Vestreng, V., Klein, H., 2002. Emission Data Reported to UNECE/EMEP: Quality Assurance and Trend Analysis \& Presentation of WebDab. MSC-W Status Report 2002. EMEP-MSC-WNote 1/2002. Meteorological Synthesizing Centre-West. Oslo, Norway.

Visvanathan, C., 1996. Hazardous waste disposal. Resource Conserv. Recycl. 16, $201-212$.

Wang, A.L., Gao, W., Hong, C., 2003. Study on the ecological effect of crop residues burned or incorporated in field in north central irrigated area of China. Chin. J. Eco Agric. 11, 142-144.

Wania, F., Daly, G.L., 2002. Estimating the contribution of degradation in air and deposition to the deep sea to the global loss of PCBs. Atmos. Environ. 36, $5581-5593$.

Wania, F., Mackay, D., Li, Y.F., Bidleman, T.F., Strand, A., 1999. Global chemical fate of alpha-hexachlorocyclohexane. 1. Evaluation of a global distribution model. Environ. Toxicol. Chem. 18, 1390-1399.

WHO (World Health Organization), 1998. Assessment of the Health Risk of Dioxin Re-evaluation of the Tolerable Daily Intake (TDI). European Centre for Environment and Health. WHO, Geneva, Switzerland.

Wu, H.L., Lu, S.Y., Li, X.D., Jiang, X.G., Yan, J.H., Zhou, M.S., Wang, H., 2012. Inhibition of PCDD/F by adding sulphur compounds to the feed of a hazardous waste incinerator. Chemosphere 86, 361-367.

Xu, W.L., Liu, J.H., 2007. Status and development prospect on municipal solid waste incineration technology in our country. China Environ. Prot. Ind. 11, 24-29.

Yan, J.H., Chen, T., Li, X.D., Zhang, J., Lu, S.Y., Ni, M.J., Cen, K.F., 2006. Evaluation of PCDD/Fs emission from fluidized bed incinerators co-firing MSW with coal in China. J. Hazard. Mater. A135, 47-51.

Yu, D., 2012. Chinese Waste: the Burning Issue. China Daily, 2013. 1. 26. Available at http://www.china.org.cn/environment/news/2009-07/28/content_18216805. htm.

Yu, Y., Huang, Y., Zhang, W., 2012. Modeling soil organic carbon change in croplands of China, 1980-2009. Glob. Planet. Change 82-83, 115-128.

Zhao, L.J., 2005. Study of Usage Inventories of Chlordane and DDT in China. Dissertation for Master of Science. Beijing University, Beijing.

Zheng, G.J., Leung, A.O.W., Li, P., Wong, M., 2008. Polychlorinated dibenzo-p-dioxins and dibenzofurans pollution in China: sources, environmental levels and potential human health impacts. Environ. Int. 34, 1050-1061.

Zheng, M.H., Sun, Y.Z., Liu, W.B., 2008. Study on Inventory of Dioxin-like POPs Emission in China. China Environmental Science Press, Beijing. 